\title{
Pollution detection, prevention and treatment using nanotechnology
}

\author{
Apoorva Sharma ${ }^{1}$, Dr. Mukesh Sharma ${ }^{2}$ \\ PG Student, Social Entrepreneurship SMLS, Tata Institute of Social Sciences, Mumbai, India ${ }^{1}$ \\ Assistant Professor, Economics, Institute of Oriental Philosophy, Vrindavan, Mathura, India ${ }^{2}$
}

\begin{abstract}
Pollution is a serious issue, and as the world's population grows, so does the need for energy and commodities, resulting in environmental repercussions. Increased solid waste output, increased air pollution from automobiles and industrial plants, and contamination of soil and groundwater are only a few of those consequences. Nanotechnology has the potential to improve the environment by using nanoparticles for detecting, preventing, and treating contaminants by removing them.

Nanoparticles have a great surface area to mass ratio, allowing them to demonstrate unique qualities that are fully exploited in nanotechnology applications. Nanotechnology can help save resources by using lightweight, high-strength carbon nanotube and metal oxide framework materials as hydrogen storage materials. The use of nanomaterials and nanoparticles in manufacturing and energy-related applications can result in significant resource savings and increased efficiency. This study investigates the use of nanotechnology in pollution detection, prevention, and treatment.
\end{abstract}

Keywords: Nanomaterials, Pollution, Nano sensors, Environment, Nanotechnology, Treatment, Detection, Prevention.

\section{INTRODUCTION}

The term "Pollution" has many definitions, one being "the presence of a substance in the environment whose chemical composition or quantity prevents the functioning of natural processes and produces undesirable environmental and health effects" (the United States Environmental Protection Agency, 2008). With rising urbanization and population, Pollution has emerged as the most pressing environmental issue. Consumption of energy and commodities is rising in tandem with global population increase, resulting in environmental effects such as increased solid waste output, increased air pollution from automobiles and industrial plants, and contamination of surface and groundwater are only a few of the repercussions. Nanotechnology has the potential to improve the environment in two ways: directly by employing nanomaterials to detect, prevent, and remove contaminants, and indirectly by adopting improved industrial design processes and producing environmentally friendly goods. There is a pressing need to develop technologies that can quickly and easily lower these rates/pollution levels to risk-free levels. A convergence of diverse sciences has led to the development of nanotechnology, which allows scientists to work at the atomic level and create these novel structures. Nanotechnology is the process of creating and managing nanoscale materials and devices in order to exploit their unique traits, such as their large surface area to mass ratio, which allows them to display unique capabilities.

Nanosensors based on nanotechnology will allow us to reliably and quickly identify and track the consequences of human activities on the environment. Finally, when pollution levels exceed acceptable limits, nanotechnology-based solutions can be utilized to mitigate environmental damage. Nanotechnology can be applied to the critical areas associated with Pollution, namely- Pollution detection and prevention and Pollution treatment/Remediation. Remediation is the science of removal or reduction of pollutants from the environment using chemical or biological means. The greatest solutions for environmental health, like human health, have three aspects: prevention, care, and treatment so that before a significant threat arises, we should carefully monitor the environment and take deliberate actions to remedy it. This research looks at how nanotechnology could be used to solve key environmental issues such as pollution detection, prevention, and treatment.

\section{POLLUTION DETECTION AND PREVENTION}

\section{Detection}

To safeguard the environment from the damaging effects of contaminants, continuous monitoring or sensing of pollutants is necessary. The maximum permitted concentration of known contaminants in the environment has been set by several environmental protection agencies. To assess the type and concentration of the pollutant present, physical, chemical, and biological techniques are available.

Even though these tests are extremely sensitive and specific, they still necessitate sample collection and processing in the lab. These techniques are time-consuming, costly, and necessitate a high level of expertise. Furthermore, these 


\section{International Advanced Research Journal in Science, Engineering and Technology}

Vol. 8, Issue 12, December 2021

\section{DOI: 10.17148/IARJSET.2021.81211}

methodologies are unable to detect the actual composition and nature of the pollutant in field conditions due to sample processing. While a sensor can help with in-field environmental monitoring, it comes at the expense of detection limit and specificity.

The goal of the research is to improve the selectivity, specificity, and sensitivity of environmental monitoring sensors, either by focusing on the contaminant-recognition element-binding or by optimizing the transduction and electronic interface to the sensing layer. Nanotechnology is helping to address these difficulties in a variety of ways. First, the nanoparticles' capacity to be coated with a wide range of chemical and biological ligands aids in the sensor's specifity. Several researchers have reported coating nanoparticles with various ligands such as proteins, DNA, enzymes, and so on. The interaction of these ligands with the analyte is very selective. Second, by altering the size and form of the nanoparticles, the surface-to-volume ratio of the nanoparticles may be easily changed, allowing for more control over the quality of the interaction with the analyte molecule. Finally, the capacity to create nanoparticles made of various metals aids in enhancing conductivity and, as a result, sensitivity. Organic impurities, inorganic contaminants, and biological organisms can all be detected using nanoparticle-based sensors.

The use of various nanostructured materials as sensors for the detection of various chemicals has been investigated. Silver nanoparticle array membranes, for example, can be employed as flow-through Raman scattering sensors to evaluate water quality. Carbon nanotubes (CNTs) have unique features that make them ideal for the creation of nanoscale chemical sensors, particularly electrochemical sensors. CNTs are used as a building block in the vast majority of sensors reported so far. CNTs' electrical resistance varies drastically when exposed to gases like NO2, NH3, or O3, owing to charge transfer with the gas molecules or physical adsorption.

The fabrication is compatible with silicon microfabrication procedures due to the potential of a bottom-up approach. When CNTs are connected to enzymes, a fast electron transfer from the enzyme's active site to an electrode is established, which in many situations improves the biomolecules' electrochemical activity. CNTs must be correctly functionalized and immobilized in order to make use of their capabilities. For glucose, ethanol, sulfide, and sequencespecific DNA analysis, CNT sensors have been constructed. Organic compound tracing analysis, such as for the medication fluphenazine, has also been observed. The use of magnetic nanoparticles coated with antibodies specific to a target bacterium for nanoimmunomagnetic labeling has been proven to be useful for the quick detection of bacteria in complex matrices.

\section{Prevention}

The decrease of pollutants at the source is known as pollution prevention. It is a promising method of environmental protection that includes a variety of activities such as using products that produce less Pollution during manufacturing, usage, or disposal. Pollution can also be avoided by reducing energy usage and minimizing the discharge of contaminants created during manufacturing operations. Pollution prevention is at the top of the pollution control hierarchy created by the pollution control legislation of 1981. Despite the importance of pollution prevention in pollution control, technology development is still primarily focused on treatment rather than prevention. Nanotechnology has the potential to help avoid Pollution. According to a recent study, employing nanotechnologybased house lighting saved the United States an estimated $\$ 100$ billion each year. The overall quantity of energy consumed was lowered by $10 \%$, and carbon emissions were cut by 200 million tonnes per year (National Nanotechnology Initiative, 2001).

Source Reduction with Nanomaterials: Metal oxide nanocatalysts, particularly gold nanocatalysts, have shown promise in preventing or decreasing Pollution at its source. Pollution control applications, such as air cleaning, low light-off autocatalysts, and purification of hydrogen streams utilized in fuel cells are used to achieve this. During 2001, 27 patents on the gold catalyst for various pollution control activities were obtained, and the number of patents has continued to rise since then. According to a World Gold Council analysis, the patents for pollution prevention by gold nanocatalyst were divided by subject, with chemical processing taking the lead with 46 percent, followed by pollution control (29 percent), catalyst manufacturing/regeneration (15 percent), and fuel cells (15 percent) (10 percent ). The major characteristic that governs gold nanocatalyst's widespread use is its high activity rate under mild settings, which lowers chemical plant operating expenses.

Furthermore, gold nanocatalysts have low activation energy and are enhanced by moisture. CO oxidation can take place at temperatures ranging from 90 to 400 degrees Celsius (Haruta, 2003). The perimeter interfaces around Au nanoparticles operate as reaction sites due to their hemispheric shape. CO adsorbs on the Au surfaces' edge and steps sites, while $\mathrm{O} 2$ adsorbs on the support surfaces. In the interface zone, both react. Carbon monoxide is oxidized much more rapidly than hydrogen using $\mathrm{Au} / \mathrm{MgO} / \mathrm{MnOx}$ at $20{ }^{\circ} \mathrm{C}$, according to Grisel and Nieuwenhuys (2001). "Mintek" of South Africa is using gold nanocatalyst in a prototype air purification machine that eliminates carbon monoxide from the air at room temperature. Restaurants, hospitals, hotels, and offices can all benefit from it. Gold nanocatalysts are also employed in fuel cells to oxidize carbon monoxide and remove it from the hydrogen feeds, making them more efficient (Cameron, Holliday, \& Thompson, 2002). Photocatalytic characteristics of titanium dioxide nanoparticles 


\section{International Advanced Research Journal in Science, Engineering and Technology}

Vol. 8, Issue 12, December 2021

\section{DOI: $10.17148 /$ IARJSET.2021.81211}

have been employed to create self-cleaning surfaces that help to reduce Pollution. When exposed to UV rays, it also acts as a powerful oxidizer. This aids in the breakdown of volatile organic compounds (VOCs), nitrous oxides (NOx), and other pollutants into less hazardous forms (Parkin \& Palgrave, 2005).

An aluminosilicate molecular sieve, often known as zeolite, is another commonly utilized structure in separation and catalysis. It is a porous crystalline solid with well-defined pores. To oxidize hydrocarbons like toluene to benzaldehyde, nanosized zeolites $(10-100 \mathrm{~nm})$ have been produced. They make oxidation environmentally favorable for two reasons. First, visible light initiates the reaction, which reduces energy usage. Second, low-energy reaction routes are used, which aid in the elimination of wasteful secondary photoreactions, hence increasing the yield of the target product (Panov, Larson, Totah, Larsen, \& Grassian, 2000).

Development that is Sustainable: Nanotechnology also aids in the production of environmentally acceptable materials by replacing harmful materials currently in use. In the production of computer monitors, Choi (1999) advocated the use of carbon nanotubes instead of cathode ray tubes (which contain lead as one of the components). Carbon nanotubebased CRT monitors reduce Pollution by removing the usage of hazardous heavy metals and substantially lowering material and energy requirements while delivering improved performance. The performance of nanoporous silicon in solar cells was investigated by Pizzini, Acciarri, and Binetti (2005). Quantum confinement and a rise in the bandgap result from its porous structure, while greater light absorption results in higher internal quantum efficiency. Gratzel (2003) developed organic solar cells employing TiO2 nanoparticles covered with an organic dye to convert light into electricity in a way similar to photosynthesis as an alternative to $\mathrm{Si}$ photovoltaics. Even though the conversion efficiency is only $10 \%$, this type of cell may be made using a simple approach using low-cost, low-purity materials. Using nanostructured electrode materials such as lithium cobalt oxide, iron fluoride, cobalt chloride, rubidium oxide, and nickel phosphide, the ALISTORE European Network of Excellence on Advanced Lithium Energy Storage Systems has been working on increasing the power output of rechargeable lithium batteries from 200 to 300 $\mathrm{Wh} / \mathrm{kg}$ (Tarascon \& Armand, 2001). To achieve effective control over the shape, size, and position of nanoscale metals employed in a catalyst, nanofabrication methods are used. Platinum group metals (PGM) are present in the ones utilized in autos. Researchers hypothesized that an automobile catalyst made with nanofabrication would have a significantly lower PGM loading level. This would reduce energy use, enhance environmental quality, and lead to resource usage that is more sustainable (Lloyd, Lave, \& Matthews, 2005).

\section{TREATMENT}

The science of removing or reducing contaminants from the environment using chemical or biological methods is known as remediation. Contaminants in soil, sediments, and water have become a significant environmental hazard as a result of recent breakthroughs. Traditional methods such as landfill disposal and isolation are somewhat effective, but they are costly and take a long time to reach the desired results (Salipira, Mamda, Krause, Malefetse, \& Durbach, 2007). These approaches also produce undesired by-products, such as dichloroethylenes and vinyl chloride, which are commonly intermediate by-products during trichloroethylene in-situ treatment. Furthermore, contaminants such as chlorinated hydrocarbons travel to the water table and occasionally reach the underlying zone, making aquifer remediation extremely challenging with current approaches. Nanotechnology can effectively attack all of these restrictions (Masciangioli \& Zhang, 2003). Because of their small size and large surface area, nanoparticles have various advantages. Because these nanoparticles are quickly carried by water (Karn, Kuiken, \& Otto, 2009), they can be employed to treat subsurface toxins without the need for excavation. These particles may be injected into very small places and even remain active for long periods of time due to their exceedingly small size (Zhang, 2003). Gravitational sedimentation controls the movement of these tiny particles to a significant extent. Enzymatic activity is high due to the enormous surface area. Nanoparticles can be anchored on a solid matrix and employed for wastewater treatment or gaseous stream treatment in addition to being used as free particles (Zhang, 2003). Carbon nanotubes, nanoscale zeolites, dendrimers, enzymes, bimetallic particles, and metal oxides are just a few of the materials that can be employed for remediation in nanotechnology.

The most widely utilized remediation tool is iron nanoparticles (Zhang, Wang, \& Lien, 1998; Ponder, Darab, \& Mallouk, 2000; Kanel, Manning, Charlet, \& Choi, 2005; Shipley, Engates, \& Guttner, 2010). Because of its reducing capabilities as an electron donor, iron plays a critical role in the cleanup of environmental contaminants. It is a potent reductant, allowing it to be used to remediate any contamination that can be degraded through reduction. Karn et al. (2009) investigated the use of iron nanoparticles to degrade polyhalogenated organic molecules and heavy metals. The halogenated organic contaminant is reduced, and iron nanoparticles are oxidized to ferric/ferrous ions during the process. Iron nanoparticles' site cleanup abilities also encompass a wide range of pollutants due to their diverse deployment ability. Fang, Si, Tian, Zhang, and Zhou have also documented successful pesticide degradation employing magnetic nanoparticles, such as 2,4 Dichlorophenoxyacetic acid (2, 4-D) (2011). Surface contaminants such as 


\section{International Advanced Research Journal in Science, Engineering and Technology}

\section{Vol. 8, Issue 12, December 2021}

\section{DOI: 10.17148/IARJSET.2021.81211}

petrochemical chemicals, as well as subsurface contaminants such as pesticides, organic solvents, fertilizers, and heavy metals, can be remedied with iron nanoparticles.

Due to magnetic and van der Waals forces, iron nanoparticles may agglomerate under certain conditions, such as when present in high concentrations. Because the particular surface area of the nanoparticles reduces and the particles settle down, this agglomeration has a negative impact on their reactivity. To address this issue, Bezbaruah, Krajangpan, Chisholm, Khan, and Bermudez (2008) used calcium alginate beads to entrap the iron nanoparticles, reducing their mobility and preventing agglomeration. They tested the efficiency of encapsulated nanoparticles against bare nanoparticles by doing degrading studies with nitrate as the model chemical. The breakdown rates of entrapped nanoparticles were found to be somewhat lower, most likely due to mass diffusion restrictions. However, statistical analysis revealed that the difference was not statistically significant. As a result, bipolymer entrapment could be used in situations where low motility and/or relatively immobile particles are required. Ponder et al. (2000) conducted a similar investigation involving immobilization with a support to prevent agglomeration by creating nanoscale particles by borohydride reduction in the presence of a support material such as polymeric resin, silica gel, etc. They compared the reduction of $\mathrm{Cr}(\mathrm{VI})$ and $\mathrm{Pb}(\mathrm{II})$ and discovered that remediation utilizing supported $\mathrm{nZVI}$ resulted in 30 times greater rates in terms of the number of moles of iron than iron powder/fillings.

The reduction or oxidation of adsorbed contaminants by semiconductor nanoparticles is dependent on the bandgap excitation of the nanoparticles. UV-radiation can either stimulate the $\mathrm{TiO} 2$ nanoparticle, resulting in the release of $\mathrm{OH}$ $/ \mathrm{OH}$. Ions/radicals that may oxidize or decrease the adsorbed contamination (Direct Method), as well as TiO2 nanoparticles, can aid in the formation of photocurrent, in which the adsorbed contaminant or dye transfers electrons to nanoparticles after being excited by visible light. The pollutant undergoes oxidative destruction in this indirect mechanism (Kamat \& Meisel, 2003). Additional alterations, such as doping semiconductor nanoparticles with transitional metal elements, have been found to improve TiO2 nanoparticles' photoresponse to visible light (Paola et al., 2002; Anpo et al., 1998). Because it emits strongly in the visual area, the ZnO semiconductor nanocluster offers promise in environmental applications. $\mathrm{ZnO}$ nanoparticles can be utilized to destroy organic pollutants like PCBs that have affixed themselves to their surface (Kamat et al., 2003).

\section{CONCLUSION}

Many changes in material characteristics occur at the nanoscale. Sensor systems can supplement and increase the efficacy of traditional analytical equipment for environmental monitoring due to their high spatial resolution and sensitivity of nano materials. This has benefits that can lead to positive outcomes, such as the development of environmental compatibility. Nanotechnology can be employed in worldwide plans in numerous environmental areas such as monitoring and reducing pollution, addressing water shortage problems, waste management, and other cases as modern science, due to its advantages and various applications. The use of nanomaterials and nanoparticles in manufacturing and energy-related applications can result in significant resource savings and increased efficiency. Nanoparticles can also be useful in catalytic and remediation applications, but their widespread dispersion in the environment could make remediation nearly impossible if there are safety concerns. Changes in characteristics at the nanoscale, on the other hand, provide challenges in terms of predicting and identifying safety and environmental issues. As a result, while adopting nanotechnology, the potential hazards should be considered. For novel nanotechnology products, a life-cycle analysis should be performed, considering various usage scenarios.

\section{ACKNOWLEDGMENT}

I'd like to extend my gratitude to coffee, painkillers, and internet. That's it. I'm done with everything and everyone.

\section{REFERENCES}

1. http://www.ijceronline.com/papers/Vol5_issue12/H05126167.pdf

2. https://iccee.journals.ekb.eg/article_34664_14a61fe6709867977d74cf8fc4bb960b.pdf

3. https://www.slideshare.net/HimanshuDixit7/nanotechnology-in-bioremediation

4. https://www.ferro-alloys.com/en/News/Details/294390

5. https://link.springer.com/content/pdf/10.1007\%2FBF03214852.pdf

6. https://application.wiley-vch.de/books/sample/352731735X_c01.pdf

7. https://www.slideshare.net/siminMaroof/nanotechnology-62455612

8. Kamat, P. V., \& Meisel, D. (2003). Nanoscience opportunities in environmental remediation. C R Chimie, 6, 999-1007. http://dx.doi.org/10.1016/j.crci.2003.06.005

9. Bezbaruah, A. N., Krajangpan, S., Chisholm, B. J., Khan, E., \& Bermudez, J. J. E. (2008). Entrapment if iron nanoparticles in calcium alginate beads for groundwater remediation applications. Journal of Hazardous Materials, 166, 1339-1343. http://dx.doi.org/10.1016/j.jhazmat.2008.12.054

10. Safaei, M.; Taran, M.; Imani, M.M. Preparation, structural characterization, thermal properties and antifungal activity of alginate-CuO bionanocomposite. Mater. Sci. Eng. C. 2019, 101, 323-329, https://doi.org/10.1016/j.msec.2019.03.108. 


\title{
International Advanced Research Journal in Science, Engineering and Technology
}

\author{
Vol. 8, Issue 12, December 2021
}

\section{DOI: $10.17148 /$ IARJSET.2021.81211}

11. Zhang, D., Anderson, M. J., Huarng, M. C., \& Alocilja, E. C. (2011). Nanoparticle-Based Biobarcoded DNA Sensor for the Rapid Detection of pagA Gene of Bacillus Anthracis. Nanotechnology, 23(21), 4756-4764. http://dx.doi.org/10.1109/TNANO.2011.2165965

12. Zhang, D., Wei, S., Kaila, C., Su, X., Wu, J., Karki, A. B., ... Guo, Z. (2010). Carbon-stabilized iron nanoparticles for environmental remediation. Nanoscale, 2, 917-919. http://dx.doi.org/10.1039/C0NR00065E

13. Zhang, W. X. (2003). Nanoscale iron particles for environmental remediation: An overview. Journal of Nanoparticle Research, 5, $323-332$. http://dx.doi.org/10.1023/A:1025520116015

14. Zhang, W. X., Wang, C. B., \& Lien, H. L. (1998). Treatment of Chlorinated organic contaminants with nanoscale bimetallic particles. Catalysis Today, 40, 387-395. http://dx.doi.org/10.1016/S0920-5861(98)00067-4

15. Zhu, L., Ang, S., \& Liu, W. T. (2004). Quantum dots as a novel immunofluorescent detection system for Cryptosporidium parvum and Giardia lamblia. Applied Environmental Microbiology, 70, 597-598. http://dx.doi.org/10.1128/AEM.70.1.597-598.2004

16. Choi, W. B. (1999). Fully sealed, high-brightness carbon-nanotube field-emission display. Applied Physics Letters, 75, $3129-3131$. http://dx.doi.org/+10.1063/1.125253

17. Fang, G., Si, Y., Tian, C., Zhang, G., \& Zhou, D. (2011). Degradation of 2,4-D in soils by Fe3O4 nanoparticles combined with stimulating indigenous microbes. Environmental Science \& Pollution Research, 19, 784-793. http://dx.doi.org/10.1007/s11356-011-0597-y

18. Goldman, E. R., Clapp, A. R., Anderson, G. P., Uyeda, H. T., Mauro, J. M., Medintz, I. L., \& Mattoussi, H. (2004). Multiplexed Toxin Analysis Using Four Colors of Quantum Dot Fluororeagents. Analytical Chemistry, 76, 684. http://dx.doi.org/10.1021/ac035083r

19. Gratzel, M., (2003) Dye sensitized solar cells. Journal of Photochemistry and Photobiology: C, 4, 145. http://dx.doi.org/10.1016/S13895567(03)00026-1

20. Grisel, R. J. H., \& Nieuwenhuys, B. E. (2001). Selective Oxidation of CO over Supported Au Catalysts. Journal of Catalysis, $199(1)$, 48-59. http://dx.doi.org/10.1006/jcat.2000.3121

21. Gupta, N., Roychoudhury, P. K., \& Deb, J. K. (2005). Biotechnology of desulfurization of diesel: prospects and challenges. Applied Microbial Biotechnology, 66(4), 356-366. http://dx.doi.org/10.1007/s00253-004-1755-7

22. Haruta, M. (2002). Catalysis and applications of gold nanoparticles deposited on metal oxides. Studies in Surface Science and Catalysis, 145, 3138. http://dx.doi.org/10.1023/A:1020181423055

23. Ho, K. C., Tsai, P. J., Lin, Y. S., \& Chen, Y. C. (2004). Using biofunctionalized nanoparticles to probe pathogenic bacteria. Analytical Chemistry, 76(24), 7162-7168. http://dx.doi.org/10.1021/ac048688b

24. Hsu, N. H., Wang, S. L, Lin, Y. C., Sheng, G. D., \& Lee, J. F. (2009). Reduction of Cr(VI) by crop residue derived black carbon. Environmental Science and Technology, 43, 8801-8806. http://dx.doi.org/10.1021/es901872x

25. Huang, Y. F., Wang, Y. F., \& Yan, X. P. (2010). Amine-Functionalized Magnetic Nanoparticles for Rapid Capture and Removal of Bacterial Pathogens. Environmental Science and Technology, 44(20), 7908-7913. http://dx.doi.org/10.1021/es102285n

26. Kamat, P. V., \& Meisel, D. (2003). Nanoscience opportunities in environmental remediation. C R Chimie, 6, $999-1007$. http://dx.doi.org/10.1016/j.crci.2003.06.005

27. Kanel, S. R., Manning, B., Charlet, L., \& Choi, H. (2005). Removal of Arsenic(III) from Groundwater by Nanoscale zero-valent iron. Environment Science and Technology, 39, 1291-1298. http://dx.doi.org/10.1021/es048991u

28. Karn, B., Kuiken, T., \& Otto, M. (2009). Nanotechnology and in Situ Remediation: A Review of the Benefits and Potential Risks. Environmental Health Perspective, 117, 1823-1831. http://dx.doi.org/10.1289/ehp.0900793

29. Li, Y. G., Gao, H. S., Li, W. L., Xing, W. L., \& Liu, H. Z. (2009). In situ magnetic separation and immobilization of dibenzothiophenedesulfurizing bacteria. Bioresource Technology, 100(21), 5092-5096. http://dx.doi.org/10.1016/j.biortech.2009.05.064

30. Limbach, L. K., Li, Y., Grass, R. N., Brunner, T. J., Hintermann, M. A., Muller, M., ... Stark, W. J. (2005). Oxide Nanoparticle Uptake in Human Lung Fibroblasts: Effects of Particle Size, Agglomeration, and Diffusion at Low Concentrations. Environmental and Science Technology, 39(23), 9370-9376. http://dx.doi.org/10.1021/es051043o

31. Lin, C. C., Yeh, Y. C., Yang, C. Y., Chen, C. L., Chen, G. F., Chen, C. C., \& Wu, Y .C. (2002). Selective Binding of Mannose-Encapsulated Gold Nanoparticles to Type 1 Pili in Escherichia coli. Journal of the American Chemical Society, 124(14), 3508-3509. http://dx.doi.org/10.1021/ja0200903

32. Liu, J., \& Lu, Y. (2004). Accelerated Color Change of Gold Nanoparticles Assembled by DNAzymes for Simple and Fast Colorimetric Pb2+ Detection. Journal of the American Chemical Society, 126(39), 12298-12305. http://dx.doi.org/10.1021/ja046628h

33. Lloyd, S. M., Lave, L. B., \& Matthews, H. S. (2005). Life cycle benefits of using nanotechnology to stabilize platinum-group metal particles in automotive catalysts. Environmental and Science Technology, 39(5), 1384-92. http://dx.doi.org/10.1021/es049325w

34. Maeda, R., Nagashima, H., Widada, J., Iwata, K., \& Omori, T. (2009). Novel marine carbazole degrading bacteria. FEMS Microbiology Letters, 292(2), 203-209. http://dx.doi.org/10.1111/j.1574-6968.2009.01497.x

35. Masciangioli, T., \& Zhang, W. X. (2003). Environmental Technologies at the nanoscale. Environ. Sci. Technol., 37, 102-108. http://dx.doi.org/10.1021/es0323998

36. Nutt, M. O., Hughes, J. B., \& Wong, M. S. (2005). Designing Pd-on-Au Bimetallic Nanoparticle Catalysts for Trichloroethene Hydrodechlorination. Environmental and Science Technology, 39, 1346-1353. http://dx.doi.org/10.1021/es048560b

37. Okx, J. P., Horijk, L., \& Stein, A. (1996). Managing soil remediation problems. Environmental Science \& Pollution Research, 3(4), $229-235$. http://dx.doi.org/10.1007/BF02986966

38. Panov, A. G., Larson, R. G., Totah, N. I., Larsen, S. C., \& Grassian, V. H. (2000). Photooxidation of Toluene and p-Xylene in Cation-Exchanged Zeolites X, Y, ZSM-5, and Beta: The Role of Zeolite Physicochemical Properties in Product Yield and Selectivity. The Journal of Physical Chemistry, B104, 5706-5714. http://dx.doi.org/10.1021/jp000831r

39. Parkin, I. P., \& Palgrave, R. G. (2005). Self-cleaning coatings. Journal of Materials Chemistry, 15, 1689. http://dx.doi.org/10.1039/B412803F Pizzini, S., Acciarri, M., \& Binetti, S. (2005). From electronic grade to solar grade silicon: chances and challenges in photovoltaics. Physica Status Solidi, A202, 2928. http://dx.doi.org/10.1002/pssa.200521104

40. Ponder, S. M., Darab, J. G., \& Mallouk, T. E (2000). Remediation of Cr(VI) and Pb(II) Aqueous solutions using supported nanoscale zero-valent iron. Environmental Science and Technology, 34, 2564-2569. http://dx.doi.org/10.1021/es9911420

41. Rickerby, D. G., \& Morrison, M. (2007). Nanotechnology and the environment: A European perspective. Science and Technology of Advanced Materials, 8(1), 19-24. http://dx.doi.org/10.1016/j.stam.2006.10.002

42. Salipira, K., Mamda, B. B., Krause, R. W., Malefetse, T. J., \& Durbach, S. H. (2007). Carbon nanotubes and cyclodextrin polymers for removing organic pollutants from water. Environmental Chemistry Letters, 5, 13-17. http://dx.doi.org/10.1007/s10311-006-0057-y

43. Shipley, H. J., Engates, K. E., \& Guttner, A. M. (2010). Study of iron oxide nanoparticles in soil for remediation of arsenic. Journal of Nanoparticle Research, 13, 2387-2397. http://dx.doi.org/10.1007/s11051-010-9999-x

44. Singh, G. B., Gupta, S., Srivastava, S., \& Gupta, N. (2011). Biodegradation of Carbazole by Newly Isolated Acinetobacter spp. Bulletin of Environmental Contamination and Toxicology, 87(5), 522-526. http://dx.doi.org/10.1007/s00128-011-0382-0 


\section{International Advanced Research Journal in Science, Engineering and Technology}

Vol. 8, Issue 12, December 2021

\section{DOI: $10.17148 /$ IARJSET.2021.81211}

45. Singh, G. B., Srivastava, A., Saigal, A., Aggarwal, S., Bisht, S., Gupta, S., ... Gupta, N. (2011). Biodegradation of carbazole and dibenzothiophene by bacteria isolated from petroleum-contaminated sites. Bioremediation Journal, 15, 189-195. http://dx.doi.org/10.1080/10889868.2011.624142

46. Stefano, L. D., Moretti, L., Rendina, I., \& Rotiroti, L. (2005). Pesticides detection in water and humic solutions using porous silicon technology. Sensors and Actuators B: Chemical, 111-112(11), 522-525. http://dx.doi.org/10.1016/j.snb.2005.03.047

47. Sugunan, A., Thanachayanont, C., Dutta, J., \& Hilborn, J. G. (2005). Heavy-metal ion sensors using chitosan-capped gold nanoparticles. Science and Technology of Advanced Materials, 6(3), 335-340. http://dx.doi.org/10.1016/j.stam.2005.03.007

48. Tarascon, J. M., \& Armand, M. (2001). Issues and challenges facing rechargeable Lithium batteries Nature, 414 , 359. http://dx.doi.org/10.1038/35104644

49. Tratnyek, P. G., \& Johnson, R. L. (2006). Nanotechnologies for environmental cleanup, Nano Today, 1, 44-48. http://dx.doi.org/10.1016/S1748$0132(06) 70048-2$

50. Tungittiplakorn, W., Cohen, C., \& Lion, L.W. (2005). Engineered Polymeric Nanoparticles for Bioremediation of Hydrophobic Contaminants. Environmental Science and Technology, 39, 1354-1358. http://dx.doi.org/10.1021/es049031a

51. Yilmaz, M. D., Hsu, S. H., Reinhoudt, D. N., Velders, A. H., \& Huskens, J. (2010). Ratiometric Fluorescent Detection of an Anthrax Biomarker at Molecular Printboards. Angewandte Chemie International Edition, 49, 5938-5941. http://dx.doi.org/10.1002/ange.201000540

52. Yonzon, C. R., Stuart, D. A., Zhang, X., McFarland, A. D., Haynes, C. L., \& Van Duyne, R. P. (2005). Towards advanced chemical and biological nanosensors-An overview. Talanta, 67, 438-448. http://dx.doi.org/10.1016/j.talanta.2005.06.039 